\section{Finding, \\ Evaluating, and Sharing New Technology}

\author{
Carli Spina, Guest Columnist \\ Carli Spina is Emerging Technologies and \\ Research Librarian at Harvard Law Library.
}

Correspondence concerning this column should be addressed to Eric Phetteplace, Emerging Technologies Librarian, Chesapeake College, 1000 College Circle, Wye Mills, MD 26179; email: ephetteplace@chesapeake.edu.
Keeping up with the plethora of apps that come out every day is challenging, whether you're a technologist or not. We all know "there's an app for that," but how do we find out which one it is? And if there are several apps for that, what are the advantages of each? One place I keep an eye on is Carli Spina's "Novel Technology" blog, where she shares new apps on a consistent schedule. In this column, she provides advice on staying current amid the flood of useful tools that are out there.-Editor

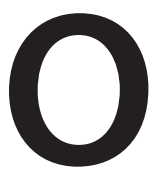

ne of the best and worst parts of working as a technology librarian is that we are always working to keep up with an ever-expanding universe of technologies and tools. This is not a situation that is unique to technology librarians; as I am sure almost any librarian would readily admit, a large part of the job is keeping abreast of new materials, whether these are new databases and sources in a subject specialty, new preservation techniques, or anything in between. Keeping up with emerging technologies in a world where new apps, plugins, and tools emerge every day can sometimes feel daunting, particularly for those who are new to the role of technologist or those for whom this is just a small piece of their job duties. The process is time consuming and necessarily involves learning about new tools that may not live up to their potential or never quite catch on and find their audience, which can occasionally make the entire process frustrating.

But even if the process can occasionally feel overwhelming, it is nevertheless important. This is an area where librarians can provide a new type of service to patrons, helping them to sift through the various options available to them. Many patrons are not technology experts and may not even realize the ways that technology can streamline their activities, provide entertainment, or offer new ways to participate in existing interests. Much as librarians have long developed print collections to meet patron needs and curated web content for quality, technology librarians now have the opportunity to provide the same services for newly emerging apps and tools.

In my experience, the best way to keep on top of these new tools as they emerge is to approach the process with a clear strategy for each step along the way, from finding new tools, to evaluating them, and finally, to sharing them. Developing a strategy will make the process more methodical and manageable, which in turn will help you to stay ahead of the curve so that you can uncover the latest gems as they emerge. 


\section{KEEPING UP WITH NEW TOOLS}

The first step in this process is necessarily finding novel tools as they emerge. But with a steady tide of new websites, apps, and tools debuting each and every day, even this seemingly simple first step requires careful thought and prioritization. No one will be able to keep up with every new tool, so I recommend asking yourself some questions to determine where your focus should lie: What groups are in your audience? Patrons may seem like the obvious answer here, but thinking beyond this simple response can be instructive in this realm just as it is in collection development. What are the demographics of your patrons? What devices do they use? Which tasks are they interested in completing both at the library and elsewhere in their lives? What common interests or pursuits exist among your patrons? And don't forget staff, who may be another discrete audience for new technologies that you discover. In the end, you may find that you have several different audiences, and knowing their needs will help you narrow your efforts to new technologies that will be of the most interest and use to one or more of your audiences.

Once you have identified your core audiences, you'll need to look for sources of information on new tools. I find that it is best to strike a balance between sources that are specifically focused on tools for the audiences you serve and sources that are more general, which might cover tools that could be adapted for your audiences or meet needs that you haven't even considered. For example, I follow several academic librarians on Twitter or via their blogs, but I also follow at least as many librarians at public libraries to learn from the types of tools they are excited about and the ways they share these tools with their patrons. In each case, following one person in a particular field has helped me to find several other equally interesting and helpful people in that field. Don't be shy about actually striking up conversations with these people either. I have found that most are happy to discuss their own strategies or the tools they like the best.

At the same time, depending on the audiences you are targeting, you may also want to follow professional organization blogs or publications, such as the YALSA Blog (http:// yalsa.ala.org/blog), which has an App of the Week feature that highlights apps of interest to young adult librarians and the teens they serve (full discolure, I am a regular contributor to YALSA Blog's App of the Week feature), or ACRL TechConnect (http://acrl.ala.org/techconnect), which covers projects and technologies from a wide range of academic libraries. Along the same lines, following the hashtags for conferences and professional development sessions (even if you can't personally attend) can be a good way of finding tools that are gaining popularity among librarians. While hashtags, which are words or phrases with \# in front of them, are best known from their use on Twitter, they have spread to other social networks as well. Many tools exist that allow you to follow them with or without a Twitter account, making them a useful tool for sorting through information on social networks. Finally, if peer institutions frequently share apps with their patrons via social media or research guides, you will want to periodically review new tools that they have identified.

While library-specific resources are a good place to start, casting a wider net has definite benefits, and a well-rounded technology research strategy should also include sources aimed at a broader audience. These sources will keep you up-to-date on the latest technologies, which may not have immediate applications at your library but will have long-term implications for your library and your patrons. And, while it may be necessary to wade through some irrelevant information in these sources, they will also often publish news about the newest tools and latest updates to existing tools much more quickly than the library-specific resources. Most are organized into categories or make use of tags that will help you to focus in on the information that is useful for your purpose. Personally, I follow Mashable (http://mashable.com), TechCrunch (http://techcrunch.com), ReadWrite (http://readwrite.com), and Wired (http://wired.com), to name just a few. Together, these sources help me to keep up on tech industry trends, new hardware, and the latest apps and tools that I might want to share with patrons and colleagues. And, even though they are general tech publications, I have frequently found tools that can be adapted for library-related uses.

\section{EVALUATING NEW TECHNOLOGIES}

Once you have found interesting new tools, the next step is to evaluate them. As with any other material that libraries provide or recommend to patrons, this is where librarians can share their expertise and add value. To do so, it is necessary to experiment with a wide range of technologies and to think critically about which criteria are relevant when evaluating them. While these criteria may vary depending on your audience, several criteria will usually be relevant.

\section{Price}

This may be the most obvious criteria for evaluating a new application, but it is important to whether the app will be recommended to patrons or be used in the library. This element also requires consideration even before evaluating any new technologies, as one of the first decisions to make is if only free tools will be promoted by your library. While many apps and tools are available for free-and it is certainly possible, and perhaps most practical for some audiences, to focus only on free products - it can also be very helpful to provide guidance about whether other apps are worth their price tag. Librarians who are evaluating technologies for in-library use or for inclusion on circulating devices will want to consider whether they have a policy to limit themselves only to free options. I generally prioritize free tools but do cover paid tools that I find particularly useful or unique. Even if you opt to focus on free tools to minimize the financial impact of the testing process, look out for free trials and products that are free while in beta. These can be great ways for you to test 
tools for free, and these free options can also be of use to patrons who want to try a tool before committing to pay for it.

\section{Platforms}

As technology has proliferated, so have the platforms on which it can be used. This can take many different forms, whether it is Mac/PC/Linux for computers, Android/iOS/ Windows/Blackberry for mobile devices, or Internet Explorer/Chrome/Firefox/Safari/etc. for web browsers. This can be one of the most difficult steps in technology review and evaluation because few will have access to all of the possible devices and platforms that might be used by patrons and colleagues. Depending on which platforms are available to you and which are the most popular among your patrons, there are a few possible approaches to this problem. For example, while I try to evaluate and test tools for as many platforms as possible, this sometimes isn't feasible, and I am therefore more likely to test and potentially recommend a tool if it is available for multiple platforms. Other possible approaches are to purchase a variety of platforms for the library or to collaborate on technology reviews with colleagues who have access to other platforms. Certainly if you are looking to create a team of librarians who identify and evaluate new tools, it makes sense to try to balance that team with people who have expertise with varying platforms.

\section{User Interface}

User interface encompasses within it a few criteria for evaluation. Primarily, it is about how usable a tool is, which includes how effective it is at its stated goals and how easy it is to learn how to use the tool, both for those who are technologically adept and those who are technophobes. It also encompasses elements of how visually pleasing the layout and design of the tool is. Finally, it is also the part of the evaluation where I would recommend looking at the tool's accessibility for those who use adaptive software or other adaptive devices. Accessibility is often overlooked in technology reviews, so this is a particular area where librarians can offer helpful information that isn't readily available elsewhere. These elements might be difficult to evaluate when you first start out reviewing new tools, but as you work with more new technologies it becomes much easier to compare them to one another and to have a sense of what makes a user interface aesthetically appealing and usable for a wide range of users.

\section{Flexibility}

When trying a new tool, I always try to think about all of the ways that it can be used and note other tools and applications with which it can integrate. Flexible tools will more seamlessly fit with existing workflows and usage patterns, which makes them useful to a wider range of users. Examples of this might include tools (such as IFTTT: https://ifttt.com) that can directly share content with other applications or social media accounts or tools (such as Dropbox: www.dropbox.com) that allow users to upload a wide range of existing files. While standalone tools might be popular with users, it is important to note how tools can work together to offer additional incentives for use and to help users increase the ways they employ existing tools.

\section{Security/Privacy}

Recently, online privacy and security have come to the forefront of the public perception and are important features to highlight for patrons. This is particularly true when reviewing technologies aimed at children and teens but should be included in any such discussion. This can mean highlighting how much information the tool collects about its users or noting how it connects to, and shares information with, social media accounts.

\section{Age Level}

Depending on the audience(s) you have identified for yourself, age appropriateness and age appeal may be important parts of the information you collect when testing a new tool. If you are a youth services librarian, it may be obvious that you will want to focus on tools that will appeal to teens and children, but even if you have a more general audience, it is worthwhile to note if the tool will appeal primarily to a specific age group because of content, style, or other features.

\section{Competitors/Alternatives}

Much as you might find readalikes for a popular book, finding alternatives to popular apps and tools can be a great way of showing the value that libraries can offer. These alternatives can fill a variety of different patrons' needs. Examples include finding free alternatives to popular tools (such as free, online PowerPoint alternatives), identifying cross-platform equivalents for trendy tools (such as finding an Android equivalent when Vine was only available to iOS devices), or finding similar games for those who have already defeated their favorite online game.

The amount of testing that you conduct on these tools and the exact way that you present your evaluations will depend on the needs you have identified and how you choose to share the technology tools with your patrons and colleagues. Neverthelesss, no matter the format, it is important to work through the evaluation process, not only so that you can select the best apps to share, but also so that you can continue to learn more about the landscape of available technology.

\section{SHARING WHAT YOU FIND}

Now that you have put in the time to find and evaluate new tools that your patrons and colleagues will love, you have to come up with a plan to share and promote these resources. 


\section{ACCIDENTAL TECHNOLOGIST}

There are many great options for sharing recommendations with patrons and colleagues both online and at events.

One successful approach that several libraries and professional organizations have taken is to share app reviews on a regular basis. Examples of this include the YALSA Blog App of the Week feature I mentioned earlier and Darien Library's recurring Appy Hour feature on Tumblr, which shares a new app selected by their staff every Thursday. ${ }^{1}$ These posts provide a brief overview of the apps, sometimes with screenshots or videos of the tools in action. If your library has a print newsletter, this can be another perfect venue for sharing technology recommendations, such as seasonal apps or new tools that fit in with existing library initiatives.

For those libraries that use LibGuides or create similar types of research guides, you can also create guides that highlight tools of interest to patrons. I have taken this approach at my library, using LibGuides to highlight software for collaboration, presentation tools, and apps for research, productivity, and fun, among other uses. Other libraries have also adopted this approach to create guides geared toward their own patron groups. ${ }^{2} \mathrm{~A}$ similar approach to share tools with colleagues is to create a technology tool section on the library's intranet. Libraries with sufficient staffing might even want to offer personalized recommendations on the basis of a questionnaire that patrons can fill out with their interests and needs.

If your library offers classes for patrons, they can also be a perfect venue for sharing new technology tools. This can take the form of classes on how to use new devices, particularly after the holidays when patrons may have received new computers, tablets, or other devices as gifts, or it can be a class at the beginning of the school year to help students get started with new productivity tools that will help them in their studies. Alternatively, libraries might offer an event where technologically savvy patrons get together and share their favorite technology tools on a particular theme, as seen at Acorn Public Library in Illinois. ${ }^{3}$ Technology tools can also be paired with other library activities or events to integrate them with the library's existing programming. Creating a guide to books about zombies? Add some apps. Hosting a cooking event? Offer a handout with some recipe apps and websites. Do genealogists frequently make use of your library? Offer classes on databases and tools that help those interested in tracing their family tree.

If you are a librarian interested in learning more about emerging technology tools and finding ways to share this information with your patrons, I hope that this column has provided some helpful tips for getting started and made it clear that you can customize this process for your own needs as well as those of your patrons. While it may seem like a daunting task when you first start, in my experience, the more tools you try the easier it is to adapt to future technologies as they emerge. Ultimately, this is just another way to offer help and advice to patrons and to extend their view of the services their library can offer.

\section{References}

1. Darien Library, Appy Hour (blog), accessed November 3, 2013, http://darienlibrary.tumblr.com/tagged/appy-hour.

2. See, for example, "Apps for Academics: Mobile Web Sites and Apps," MIT Libraries, accessed November 3, 2013, http://libguides mit.edu/apps.

3. Acorn Public Library District, "Want to Get 'Appy'?" (promotional flyer), accessed November 3, 2013, http://acornlibrary.org/pdf/@ corn $\% 20$ connects.pdf. 